\title{
PHYSIOLOGICAL ADAPTATIONS OF TWO SPECIES OF CENTIPEDE (CHILOPODA: GEOPHILOMORPHA) TO LIFE ON THE SHORE
}

\author{
By JoHN BiNYoN \\ Department of Zoology, Royal Holloway College, London \\ AND J. G. E. LEWIS \\ Department of Zoology, University of Khartoum, Sudan
}

(Text-figs. I, 2)

Of the five orders which comprise the class Chilopoda only one, the Geophilomorpha, contains species restricted to the littoral zone and experiencing frequent immersion in sea water. Three such species are found at Plymouth. These are Strigamia (= Scolioplanes) maritima (Leach), Hydroschendyla submarina (Grube) and Geophilus fucorum seurati Brölemann (Lewis, 1962). $S$. maritima is commonly found in shingle and rock crevices from the storm line to the Verrucaria zone, $H$. submarina in rock crevices from the Verrucaria zone down to about mid-tide level. G. fucorum seurati is found with $S$. maritima, but only rarely, and was consequently not used in the present investigation.

Shore-dwelling centipedes meet an aquatic environment with a high osmotic pressure and this presents a problem which can be overcome either by regulation of the animal's internal osmotic pressure or by allowing the concentration of the body fluid to follow that of the environment. The present work is an investigation into the methods by which these two species have adapted to this situation, comparison being made with the terrestrial Haplophilus subterraneus (Shaw).

H. submarina, occurring as it does down to mid-tide level, is frequently immersed in sea water. S. maritima which occurs only at the top of the shore in the Plymouth area is less frequently in contact with sea water, but it feeds almost exclusively on marine invertebrates, principally Orchestia gammarella (Pallas) in this locality. The body fluids of this crustacean have been shown by one of us (J.B.) to be isotonic with sea water.

\section{MATERIALS AND METHODS}

Strigamia maritima was collected from shingle around HWM in a small cove at the northern end of Jennycliff Bay and Hydroschendyla submarina from 
rock crevices at Cawsand Bay. Haplophilus subterraneus was collected from soil on waste ground at the western end of Plymouth Hoe.

The weight changes of animals completely immersed in normal and diluted sea water were measured by placing them in a polystyrene pill-box $5 \mathrm{~cm}$ in diameter and $3 \mathrm{~cm}$ deep, the bottom of which had been removed and covered with fine bolting silk and whose lid was pierced at the corner by a small hole. Animals were placed in these chambers and three such chambers placed in a larger polystyrene box of $500 \mathrm{ml}$. capacity containing the sea water of the required dilution. The air in the chambers was expelled through the small hole in the lid which was then plugged with plasticine and the chambers inverted so as to allow free diffusion between the chamber and the surrounding medium. The chambers were removed at intervals, drained, and the centipedes lightly blotted with absorbent tissue and weighed. Animals which showed no movement on being lightly prodded with a blunt seeker were presumed dead and rejected. Experimental animals were kept in a constant temperature room at $17^{\circ} \mathrm{C} \pm \mathrm{I}^{\circ} \mathrm{C}$.

Body fluid samples from these species were obtained by the following procedure. The experimental animal was lightly narcotized with ether and placed on a clean glass slide. Small incisions were made on each side of the animal five segments behind the head. The posterior end was held down with slight pressure from the finger, and the head pulled away from the rest of the body. This ruptured the cuticle around the fifth segment so that the oesophagus and salivary glands could be pulled out of the body. The oesophagus was cut at its junction with the mid-gut. The process was repeated at a point three segments from the posterior end and the mid-gut, hind-gut and reproductive organs removed leaving a tube of exoskeleton containing the body wall musculature, heart, nervous system, connective tissue, fat body and much of the body fluid. This tube was held closed at its posterior end and the body fluid expressed from the anterior end by rolling a seeker along the outside of the tube. With the exception of the fat body which occasionally emerged with the last drop of body fluid, the organ systems remained within the exoskeletal tube. The drop of body fluid obtained was immediately drawn into a capillary and centrifuged. The detritus thrown down by this operation was removed by cutting off the tip of the capillary and the length of fluid remaining in the tube was then measured before its transfer to either the wire loop of a Baldes-Hill thermo-osmometer for the determination of the osmotic pressure, or a small polythene tube for dilution and estimation of the sodium concentration by means of an 'EEL' flame photometer. An identical volume of a standard sodium solution was treated in a similar way. The standard deviation for the determination of the osmotic pressure was $0.5 \%$ sea water and that for sodium $2.5 \%$ sea water. 


\section{WEIGHT CHANGES IN NORMAL AND DILUTED \\ SEA WATER}

The change in weight of batches of three specimens of Hydroschendyla and Strigamia and of individual Haplophilus in normal, 60\% and 10\% sea water was measured by using the immersion chambers described above. The results are presented in Fig. I.

In all three species the weight changes were minimal in $60 \%$ sea water. They gained weight in 10\% sea water and lost weight in normal sea water. Haplophilus exhibited the greatest changes in weight, Hydroschendyla the least, and Strigamia was intermediate between the two. The changes in weight observed were presumably due to movement of water across the body wall, possibly enhanced or reduced as the case may be by a movement of salts. The smaller and slower changes in weight seen in Hydroschendyla and Strigamia as compared with Haplophilus may be due to the possible possession by the former species of less permeable cuticles. It would seem reasonable to suppose, therefore, that all these species are in osmotic equilibrium with about $60 \%$ sea water.

It was considered of interest in connexion with the above experiment and with their life on the shore, to determine the longevity of each species when completely submerged in normal and diluted sea water. Accordingly, a number of animals were kept in the plastic chambers in normal, $60 \%$ and $10 \%$ sea water and examined periodically. The results are presented in Table I and indicate that the species normally living farthest down the shore, namely Hydroschendyla, survived longest under conditions of total immersion in all three solutions.

\section{OSMOTIC PRESSURE AND SODIUM CONCENTRATION OF THE BODY FLUIDS}

No previous records exist for either the osmotic pressure or sodium concentration in the body fluids of the Chilopoda. Table 2 presents values obtained for the osmotic pressure and sodium concentration of the coelomic fluid of the three species investigated. It will be seen that the total osmotic pressure is similar in all cases and that it varies from 44 to $50 \%$ of the sea water value. Under these conditions of osmotic pressure the littoral species will be hypotonic when immersed in sea water and consequently in danger of desiccation. The sodium concentration accounts for approximately $50 \%$ of the total osmotic pressure and thus only a small residue is left to be accounted for, which is probably due to colloids. It was found impossible to maintain the terrestrial Haplophilus in sea water for any length of time and even after a period of $4.5 \mathrm{~h}$ the sodium concentration had risen by nearly $70 \%$ and the animals were dying. The littoral species were unaffected by $\mathrm{I} 4 \mathrm{~h}$ immersion, and this evidence, taken in conjunction with the weight changes in diluted sea water, would further suggest that they possessed a less permeable cuticle. 

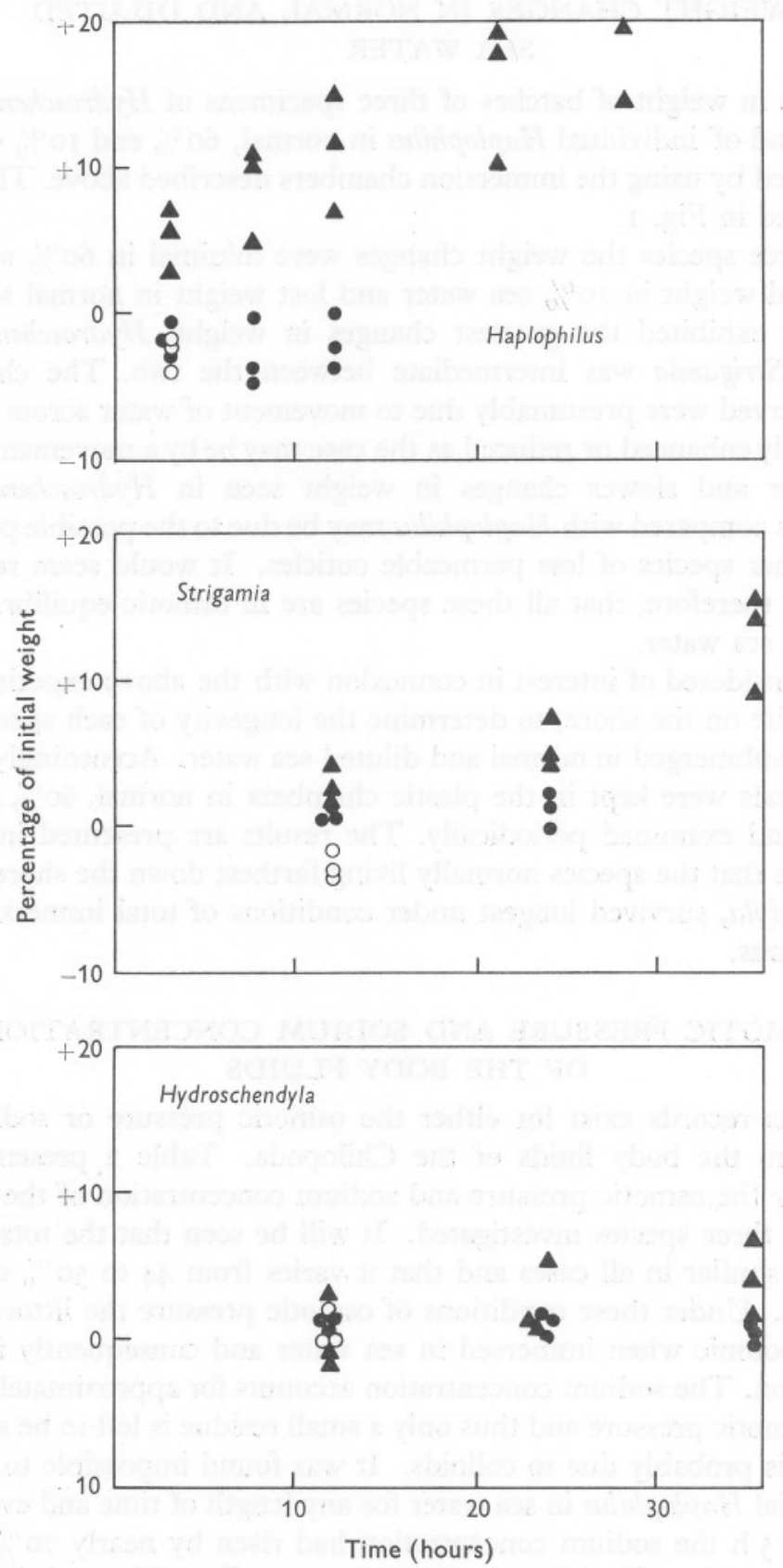

Fig. I. Change in weight of three species of centipede when immersed in normal, $60 \%$ and I0 $\%$ sea water. O, Normal sea water; $\bullet 60 \%$ sea water; $\boldsymbol{\Lambda}$, I0 $\%$ sea water. 
TABLE 1. LONGEVITY OF CENTIPEDES IN NORMAL AND DILUTED SEA WATER

(All experiments were conducted at $17^{\circ} \mathrm{C}$.)

\begin{tabular}{lccc}
\multicolumn{1}{c}{ Genus } & I0 $\%$ & $60 \%$ & 100 \% \\
Haplophilus & sea water & sea water & sea water \\
Strigamia & $30-46 \mathrm{~h}$ & 12-2 $\mathrm{h}$ & $4-8 \mathrm{~h}$ \\
Hydroschendyla & $36-72 \mathrm{~h}$ & $12-36 \mathrm{~h}$ & $12-24 \mathrm{~h}$ \\
& $48-84 \mathrm{~h}$ & $36-48 \mathrm{~h}$ & $12-36 \mathrm{~h}$
\end{tabular}

TABLE 2. OSMOTIC PRESSURE AND SODIUM CONCENTRATION OF THE COELOMIC FLUIDS

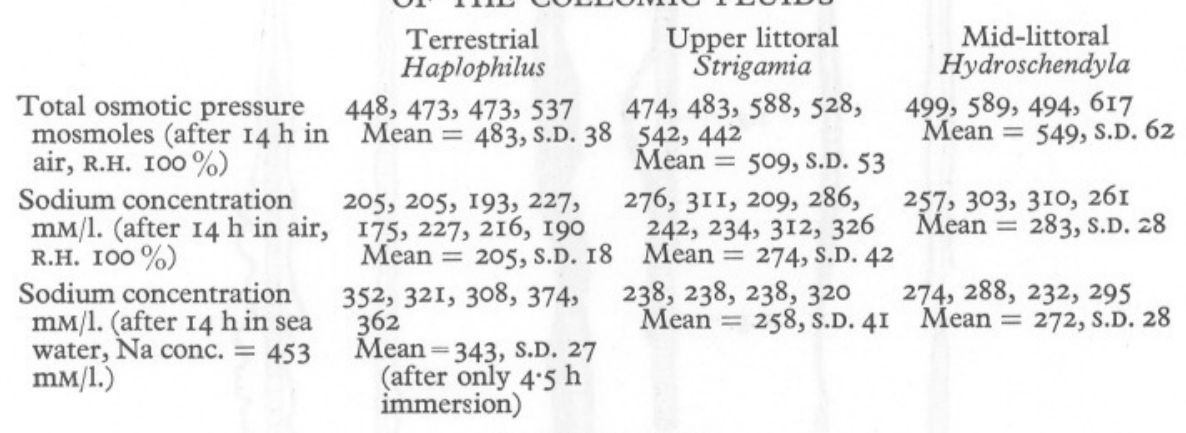

\section{DISCUSSION}

To have attained isotonicity with their environment would have obviated the need for the littoral Chilopoda to use energy in making good the water lost osmotically during immersion. They do indeed appear to be slightly less permeable than their terrestrial relative Haplophilus; nevertheless, a certain amount of water is lost under these conditions of immersion. Even after I4 $\mathrm{h}$, however, the concentration of sodium in the body fluids had not risen significantly, which means that salt too must have been lost. It is clearly impossible for this to occur by simple diffusion and an active secretion of ions to the exterior must take place. In this respect the littoral Chilopoda are in a position analogous to that of the marine teleost which overcomes the problem of osmotic desiccation by drinking quantities of sea water and secreting the excess salt back into the sea across its gills. A somewhat similar situation has recently been shown by Croghan (1958) to occur in Artemia salina L. Whereas in both these examples a definite morphological site of ion transport can be ascribed, it was not possible in the case of these littoral centipedes to demonstrate any regions of increased permeability to salt by the silver-uptake method. However, the gross anatomy of the terrestrial and littoral species differs in one rather striking particular. The salivary glands of littoral species are much larger relative to the body than are those of the terrestrial ones. This can be seen in Fig. 2 which shows the relative size of the salivary glands of Hydroschendyla submarina and the terrestrial Schendyla nemorensis (C. L. Koch) (Schendylidae), Strigamia maritima and the terrestrial Strigamia 
acuminata (Leach)(Geophilidae), and Haplophilus subterraneus(Himantariidae) and Henia bicarinata (Meinert) (Geophilidae) a littoral species collected from Posidonia drift at Banyuls-sur-Mer on the Mediterranean coast of France.

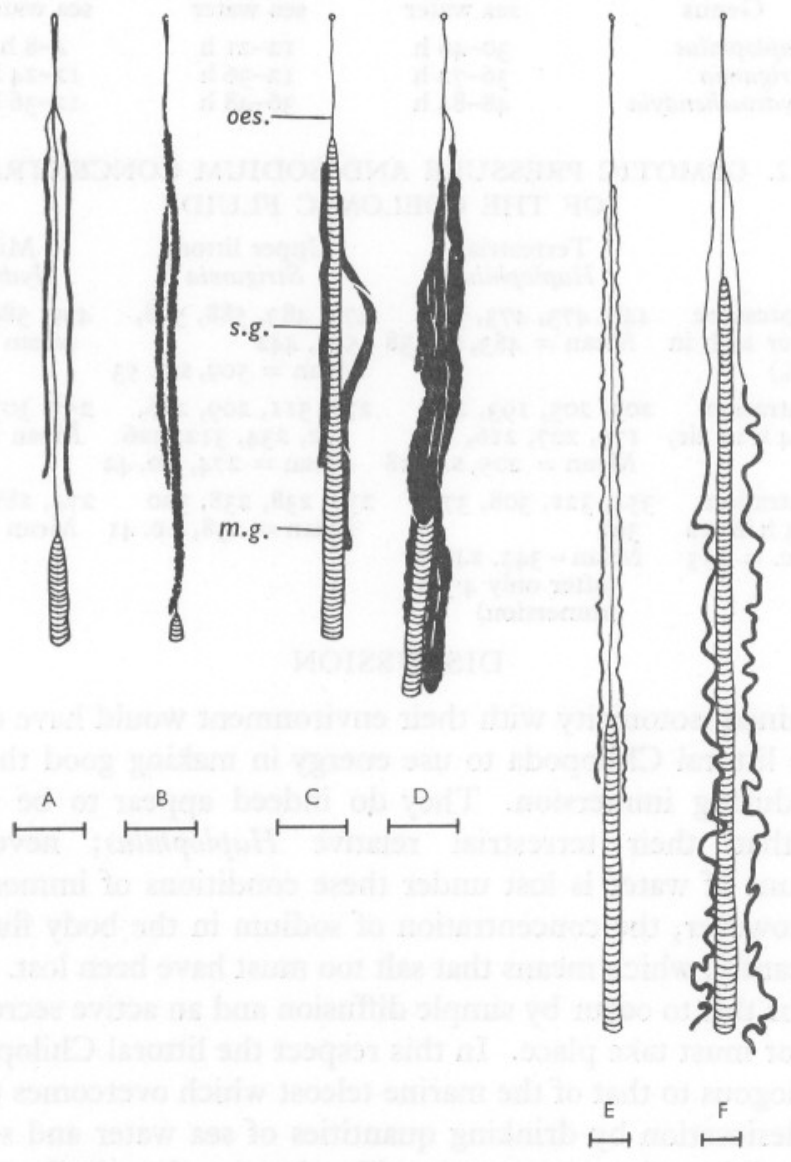

Fig. 2. Salivary glands of three species of littoral and three species of terrestrial centipede drawn from whole mounts, stained with borax carmine. All scale lines $=1 \mathrm{~mm}$. A, Schendyla nemorensis (terrestrial); B, Hydroschendyla submarina (littoral); c, Strigamia acuminata (terrestrial); D, Strigamia maritima (littoral); E, Haplophilus subterraneus (terrestrial); F, Henia bicarinata (littoral). oes., Oesophagus; s.g., salivary gland; m.g., mid-gut.

It is unlikely that these differences are due to the diet of these animals and it is suggested that the enlarged glands of the littoral species could well be the site of salt secretion. It has not been possible so far to determine whether the animal in fact drinks the medium in order to make good its water loss, but in any case there is the excess salt in the food to be removed. Buccal and nasal glands have previously been shown to be of importance in the maintenance of 
the correct osmotic pressure in whales (Fetcher, 1939) and marine birds (Schmidt-Nielsen, Jorgensen \& Osaki, I958).

We would like to thank the Director and Staff of the Laboratory of the Marine Biological Association of the U.K. for their hospitality and help during the course of this work.

\section{SUMMARY}

The osmotic pressure and sodium concentration of the coelomic fluid of two species of littoral centipede have been measured and compared with those of a terrestrial one. A similar value of about $45 \%$ sea water was obtained for all three species. Weight changes and longevity experiments in normal and diluted sea water suggest that littoral species are less permeable than terrestrial ones and it is suggested that the enlarged salivary glands of littoral species could be the site of salt secretion. A comparison is drawn with teleost and other examples whose body fluids are hypotonic to their environment.

\section{REFERENCES}

Croghan, P. C., I958. The mechanism of osmotic regulation in Artemia salina (L.): The physiology of the branchiae. F. exp. Biol., Vol. 35, pp. 234-43.

Fetcher, E. S., I939. The water balance in marine animals. Quart. Rev. Biol., Vol. I4, pp. $45 \mathrm{I}-9$.

LEwIS, J. G. E., I962. The ecology, distribution and taxonomy of the centipedes found on the shore in the Plymouth area. F. mar. biol. Ass. U.K., Vol. 42, pp. $655-64$.

SChMidT-Nielsen, K., JoRgensen, C. B., OSAKi, H., I958. Extrarenal salt excretion in birds. Amer. F. Physiol., Vol. 193, pp. IOI-7. 